\title{
Urbano-geografsko proučevanje blokovskih stanovanjskih sosesk kot element urbanističnega planiranja
}

\author{
Dejan Rebernik \\ Dr., Oddelek za geografijo, Filozofska fakulteta, Univerza v Ljubljani, \\ Aškerčeva 2, 1000 Ljubljana, Slovenija \\ e-mail: dejan.rebernik@guest.arnes.si
}

\section{Izvleček}

$\checkmark$ prispevku je predstavljena raziskava o odnosu prebivalstva blokovskih stanovanjskih sosesk v Ljubljani do svojega bivalnega okolja in možnosti njene uporabe $v$ urbanističnem planiranju. Namen raziskave je s pomočjo anketiranja prebivalstva izbranih blokovskih stanovanjskih sosesk ugotoviti značilnosti zaznavanja in vrednotenja svojega bivalnega okolja, izbire lokacije in tipa stanovanja ter potencialne selitvene mobilnosti.

Ključne besede: urbana geografija, behaviourizem, urbanistično planiranje, blokovske stanovanjske soseske, Ljubljana

\section{Urban Geography of High-Rise Housing Estates and its Application in Urban Planning}

\begin{abstract}
Research about perception and evaluation of living environment by the population of high-rise housing estates in Ljubljana and its potential application in urban planing is presented in the paper. By the use of questionnaire surveys in different high-rise housing estates characteristics of residential location decisions and potential intraurban migrations are defined.
\end{abstract}

Key words: urban geography, behaviourism, urban planning, high-rise housing estates, Ljubljana 


\section{BLOKOVSKE STANOVANJSKE SOSESKE V SLOVENIJI}

Razvoj slovenskih mest po letu 1945 sta zaznamovali dve osnovni obliki stanovanjske gradnje, na eni strani "družbena gradnja" blokovskih stanovanjskih sosesk in na drugi strani "individualna" gradnja enodružinskih hiš.

Družbena stanovanjska gradnja je bila močno favorizirana vse do konca osemdesetih let. Najintenzivnejša gradnja blokovskih stanovanjskih sosesk je značilna za šestdeseta, sedemdeseta in prvo polovico osemdesetih let. Pomen družbene stanovanjske gradnje je bil v mestih praviloma večji. Tako je v nekdanjih petih ljubljanskih občinah delež zgrajenih družbenih stanovanj po posameznih letih dosegal med $60 \%$ in $90 \%$.

Najvišji obseg je družbena stanovanjska gradnja dosegla me leti 1975 in 1985, ko je bilo zgrajeno med 8000 in 10000 stanovanj letno, samo v Ljubljani med 1500 in 2500. (tabela 1). Po letu 1985 se je obseg družbene stanovanjske gradnje začel zmanjševati. Leta 1989 je bil ukinjen sistem financiranja družbene stanovanjske gradnje. Leta 1991 je bil sprejet stanovanjski zakon, ki je uvedel odkup družbenih stanovanj, ustanovitev stanovanjskega sklada in izdelavo nacionalnega stanovanjskega programa. Ob močno zmanjšani družbeni stanovanjski gradnji se je razmahnila komercialna stanovanjska gradnja za trg. Vse to je močno vplivalo na značilnosti stanovanjskega trga in stanovanjske gradnje ter posredno na socialnogeografsko preobrazbo slovenskih mest.

Rezultat takšne stanovanjske politike je dejstvo, da so blokovske stanovanjske soseske postale najbolj značilna in razširjena oblika stanovanjske gradnje in stanovanjskih območij v slovensklih mestih. Velik del prebivalstva, v Ljubljani na primer približno ena polovica, živi v blokovskih stanovanjskih soseskah iz šesdesetih, sedemdesetih in osemdesetih let. V Mestni občini Ljubljana je več kot polovica stanovanj v blokovskih soseskah zgrajenih po letu 1945 (okoli 60000 od 110000 stanovanj).

Proučevanje blokovskih stanovanjskih sosesk je zato ena izmed nalog slovenske urbane geografije. V Evropi, predvsem pa v tranzicijskih državah Srednje in Vzhodne Evrope, je bilo v zadnjih letih blokovskim stanovanjskim soseskam namenjeno veliko pozornosti, saj le te predstavljajo najbolj "problematičen" del stanovanjskega fonda (Stollber-Barkley, 2001). Za blokovske stanovanjske soseske je tako značilna fizična in socialna degradacija, koncentracija "marginalnih" družbenih skupin, pojavljanje kriminala, vandalizma in drugih družbeno nezaželenih oblik obnašanja ter posledično nezadovoljstvo stanovalcev z bivalnim okoljem, negativna podoba blokovskih stanovanjskih sosesk $\mathrm{v}$ javnosti, padanje cen nepremičnin in podobno. 
Urbano-geografsko proučevanje blokovskih stanovanjskih sosesk...

Tabela 1: Zgrajena stanovanja v Sloveniji glede na tip investitorja, $1968-1994^{1}$

\begin{tabular}{|c|c|c|c|c|c|}
\hline Leto & $\begin{array}{c}\text { Zgrajena } \\
\text { stanovanja }\end{array}$ & $\begin{array}{c}\text { Zgrajena } \\
\text { družbena } \\
\text { stanovanja }\end{array}$ & $\begin{array}{c}\text { Delež } \\
\text { zgrajenih } \\
\text { družbenih } \\
\text { stanovanj (\%) }\end{array}$ & $\begin{array}{c}\text { Zgrajena } \\
\text { zasebna } \\
\text { stanovanja }\end{array}$ & $\begin{array}{c}\text { Delež } \\
\text { zgrajenih } \\
\text { zasebnih } \\
\text { stanovanj (\%) }\end{array}$ \\
\hline 1968 & 9375 & 5089 & 54 & 4286 & 46 \\
\hline 1969 & 9088 & 4364 & 48 & 4724 & 52 \\
\hline 1970 & 9261 & 3959 & 43 & 5302 & 57 \\
\hline 1971 & 10269 & 4818 & 47 & 5451 & 53 \\
\hline 1972 & 10221 & 5408 & 53 & 4813 & 47 \\
\hline 1973 & 11504 & 6331 & 55 & 5173 & 45 \\
\hline 1974 & 13793 & 8079 & 59 & 5717 & 41 \\
\hline 1975 & 15893 & 9750 & 61 & 6143 & 39 \\
\hline 1976 & 14465 & 8536 & 59 & 5929 & 41 \\
\hline 1977 & 14975 & 8164 & 55 & 6811 & 45 \\
\hline 1978 & 14014 & 8057 & 57 & 5957 & 43 \\
\hline 1979 & 13820 & 7422 & 54 & 6398 & 46 \\
\hline 1980 & 13672 & 6999 & 51 & 6673 & 49 \\
\hline 1981 & 14674 & 8281 & 56 & 6393 & 44 \\
\hline 1982 & 13245 & 7051 & 53 & 6140 & 46 \\
\hline 1983 & 12344 & 5634 & 46 & 6710 & 54 \\
\hline 1984 & 11612 & 4910 & 42 & 6702 & 58 \\
\hline 1985 & 11252 & 5114 & 45 & 7138 & 63 \\
\hline 1986 & 12937 & 4887 & 38 & 8050 & 62 \\
\hline 1987 & 10212 & 3963 & 39 & 6249 & 61 \\
\hline 1988 & 9799 & 3684 & 38 & 6115 & 62 \\
\hline 1989 & 8541 & 2260 & 26 & 6281 & 74 \\
\hline 1990 & 7759 & 2246 & 29 & 5513 & 71 \\
\hline 1991 & 5918 & 1332 & 23 & 4586 & 77 \\
\hline 1992 & 6492 & 1349 & 21 & 5143 & 79 \\
\hline 1993 & 7846 & 794 & 10 & 7052 & 90 \\
\hline 1994 & 5522 & 538 & 10 & 4984 & 90 \\
\hline
\end{tabular}

\footnotetext{
${ }^{1}$ Vir : Brezar, Vladimir: Stanovanjska izgradnja v Sloveniji včeraj in danes, Urbani izziv 28 - 29, Urbanistični inštitut, Ljubljana, 1995
} 


\section{BEHEVIOURISTIČNI PRISTOP PRI PROUČEVANJU SOCIALNE GEOGRAFIJE MESTA}

Behaviouristična geografija se je oblikovala sredi šestdesetih let kot reakcija in kritika pozitivizma v geografiji. Gre za več različnih pristopov, ki pa jih združuje izhodišče, da je proučevanje posameznika ter njegovega zaznavanja, vrednotenja in preoblikovanja okolja temeljna naloga geografije. Zagovorniki behaviouristične smeri so bili posebno kritični do predpostavke pozitivističnega geografskega proučevanja, da lahko človeško obnašanje razumemo kot skupek racionalnih odločitev »ekonomskega človeka« (Jackson in Smith, 1984, str. 48). Behaviouristična geografija poudarja individualnost in subjektivnost odločitev posameznika, saj jih pogojujejo številni psihološki, socialni in drugi vzgibi. Kljub poudarjanju individualnosti in subjektivnosti pa so tudi behaviouristični geografi iskali splošne vzorce in zakonitosti človeškega obnašanja, zato lahko tudi beheviouristično geografijo razumemo kot nadaljevanje pozitivistične tradicije (Hall, 1998, str. 22).

Središče zanimanja raziskovanja tako postane obnašanje posameznika $\mathrm{v}$ mestnem prostoru, $\mathrm{v}$ okviru socialne urbane geografije predvsem izbira lokacije stanovanja. Rezultat takšnih proučevanj so modeli stanovanjske izbire, ki poskušajo individualne, naključne in subjektivne odločitve posameznikov o izbiri lokacije in tipa stanovanja povezati $\mathrm{v}$ splošno veljaven in aplikativen sistem. Individualno gospodinjstvo je izpostavljeno dvema vrstama pritiskov : na eni strani notranji (potrebe, želje in vrednote gospodinstva samega) in na drugi strani zunanji pritiski (značilnosti stanovanja in soseske). Rezultat soočanja obeh vrst pritiskov je "uporabnost prostora" ("place utility"), ki predstavlja individualno stopnjo zadovoljstva (ali nezadovoljstva) z določenim stanovanjem in lokacijo. Če je neskladje med "uporabnostjo prostora" in potrebami določenega gospodinjstva dovolj velika, bo le to iskalo novo lokacijo (Carter, 1995, str. 235). Posebno velik vpliv na spremenjene potrebe gospodinjstva ima spremenjen družinski, pa tudi socioekonomski položaj.

Selitve prebivalstva znotraj mesta tako odločilno prispevajo k oblikovanju socialnogeografske zgradbe mesta in so osnovni vzvod procesov socialnogeografske preobrazbe. Ob tem Špesova ugotavlja, da v slovenskih razmerah kronično pomanjkanje stanovanj v veliki meri zavira tovrstno diferenciacjo prebivalstva. Predpostavlja, da bo do večje prerazporeditve prebivalstva glede na njegove možnosti, potrebe, želje in predstave prišlo v prihodnjih letih, ko bo v tržnih razmerah prihajalo do izrazitejšega socialnega razslojevanja prebivalstva (Špes, 1998, str. 19). 


\section{UPORABA BEHAVIOURISTIČNEGA PRISTOPA PRI PROUČEVANJU BLOKOVSKIH STANOVANJSKIH SOSEK V LJUBLJANI}

Namen raziskave je s pomočjo anketiranja prebivalstva izbranih blokovskih stanovanjskih sosesk v Ljubljani ugotoviti značilnosti zaznavanja in vrednotenja svojega bivalnega okolja, izbire lokacije in tipa stanovanja ter potencialne selitvene mobilnosti.

Osnovna metoda, ki smo jo uporabili za ugotavljanje odnosa prebivalstva do svojega bivalnega okolja, je bilo anketiranje prebivalstva. Izvedli smo 589 anket $^{2}$ med naključno izbranimi gospodinjstvi $\mathrm{v}$ devetih blokovskih stanovanjskih soseskah v Ljubljani. Anketa je tako posredno skupno zajela okoli 1700 prebivalcev oziroma okoli $5 \%$ prebivalstva proučevanih blokovskih sosesk. Anketni vprašalnik je razdeljen v tri skupine vprašanj :

- Podatki o gospodinjstvu (ugotavljanje osnovnih značilnosti gospodinjstva glede velikosti, starosti, poklicne in izobrazbene strukture).

- Podatki o stanovanju in stanovanjski zgradbi (ugotavljanje osnovnih značilnosti stanovanja ter stanovanjske zgradbe in njihove ustreznosti za gospodinjstvo)

- podatki o zaznavanju in vrednotenju bivalnega okolja (ugotavljanje osnovnih značilnosti odnosa prebivalstva do svojega bivalnega okolja in ugotavljanje potencialne selitvene mobilnosti)

$\mathrm{V}$ raziskavo je bilo vključeno devet blokovskih stanovanjskih sosesk v Ljubljani, od najstarejših zgrajenih v petdesetih letih prejšnega stoletja (Litostrojski bloki), do najnovejših (Bežigrajski dvor in Nove Poljane). Soseski Na Jami in Savsko naselje sta bili zgrajeni v šestdesetih letih, soseske Bratov Babnik, Brilejeva, Nove Fužine in Trnovski pristan pa v osemdesetih letih.

S prvim sklopom vprašanj smo poskušali oceniti družinski in socioekonomski položaj anketiranih gospodinjstev po posameznih lokacijah.. Predvsem nas je zanimalo, ali se odnos prebivalstva do bivalnega okolja razlikuje po posameznih socialnih skupinah prebivalstva oziroma ali gospodinjstva z različnim socioekonomskim in družinskim položajem drugače vrednotijo svoje bivalno okolje. Na osnovi izhodišč behaviouristične smeri v urbani geografiji lahko percepcijo in vrednotenje predstavnikov posameznih socialnih skupin prebivalstva razumemo kot reprezentativne za celotno socialno skupino.

Podatki o lastniški strukturi stanovanj anketiranih gospodinjstev kažejo na prevlado lastniških stanovanj. Visok delež najemnih stanovanj je značilen

\footnotetext{
${ }^{2}$ Anketiranje so izvedli študenti geografije v okviru predmeta Urbana geografija v letu 2002
} 
le za sosesko Nove Poljane, kjer v večjem delu soseske prevladujejo stanovanja v lasti Mestne občine Ljubljana, takoimenovana "neprofitna" stanovanja. Za vse soseske zgrajene pred letom 1990 je bil značilen visok delež družbenih stanovanj. Po odkupu stanovanj po stanovanjskem zakonu iz leta 1991 se je delež družbenih stanovanj v Ljubljani od 41.8 \% zmanjšal na $10 \%$ (Stanovnik, 1995). Večina imetnikov stanovanjske pravice se je torej odločila za odkup stanovanja pod pogoji, ki jih je nudil stanovanjski zakon iz leta 1991. Med razlogi za odkup stanovanja je bil najpogostejši odgovor ugodna cena oziroma ugodni pogoji plačila. Veliko anketirancev je kot razlog navedlo tudi željo po lastništvu stanovanja. Pri starejših gospodinjstvih je bil pogost razlog občutek socialne varnosti (značilen je odgovor "zaradi varnosti na stara leta"). Med najemniki so prevladovala gospodinjstva, ki so stanovanje najemala od fizične osebe, gre torej za stanovanja $\mathrm{v}$ takoimenovanem "privatnem" najemu. Med najemniki so najbolj zastopani študenti, mlajše samske osebe ali pari ter mlade družine.

Tabela 2: Vrednotenje ustreznosti stanovanja in potencialna selitvena mobilnost

\begin{tabular}{|l|c|c|}
\hline $\begin{array}{l}\text { Blokovske } \\
\text { stanovanjske soseske }\end{array}$ & $\begin{array}{c}\text { Delež gospodinjstev } \\
\text { nezadovoljnih s stanovanjem } \\
(\%)\end{array}$ & $\begin{array}{c}\text { Delež gospodinjstev, ki } \\
\text { se namerava preseliti } \\
\text { (\%) }\end{array}$ \\
\hline Litostrojski bloki & 26 & 39 \\
\hline Na Jami & 28 & 42 \\
\hline Savsko naselje & 29 & 35 \\
\hline Bratov Babnik & 39 & 46 \\
\hline Nove Fužine & 25 & 46 \\
\hline Brilejeva & 24 & 36 \\
\hline Trnovski pristan & 23 & 26 \\
\hline Bežigrajski dvor & 22 & 25 \\
\hline Nove Poljane & 10 & 12 \\
\hline
\end{tabular}

Rezultati raziskave kažejo na relativno visoko selitveno mobilnost po letu 1991. Le ta je pogojena predvsem s povečanim deležem lastniških stanovanj in posledičnim razvojem nepremičninskega trga. Posebno izstopajo starejše soseske Litostrojski bloki, Na Jami in Savsko naselje ter soseska Bratov Babnik. Visoko selitveno mobilnost izkazujejo $\mathrm{v}$ prvi vrsti najemniki stanovanj, $\mathrm{v}$ starejših blokovskih soseskah pa tudi lastniki stanovanj. Delež priseljenih v novo stanovanje, torej prebivalcev, ki v stanovanju bivajo od izgradne soseske, je v starejših soseskah le med $20 \%$ in $35 \%$. Približno $25 \%$ lastnikov stanovanj pa se je priselilo v zadnjih 10 letih. Razlog za višjo selitveno mobilnost v 
starejših soseskah je prav gotovo visoka umrljivost starejšega prebivalstva. V stanovanja se naselijo dediči oziroma jih prodajo. Drugi pogost razlog za prodajo stanovanja in odselitev je neustrezen stanovanjski standard, predvsem premajhna stanovanja.

Osrednji del raziskave je bil namenjen ugotavljanju odnosa prebivalstva do bivalnega okolja. Zanimalo nas je, ali so gospodinjstva zadovoljna s svojim stanovanjem, ali se nameravajo v prihodnosti preseliti in kako ocenjujejo kvaliteto bivalega okolja v svoji soseski.

Delež gospodinjstev, ki s svojim stanovanjem ni zadovoljen, se giblje med $40 \%$ v soseski Bratov Babnik in $10 \%$ v soseski Bežigrajski dvor. Relativno veliko gospodinjstev je nezadovoljnih s svojim stanovanji tudi v starejših soseskah Litostrojski bloki, Na Jami in Savsko naselje, nekoliko manj pa v soseskah Nove Fužine in Brilejeva. Zadovoljstvo oziroma nezadovoljstvo s stanovanjem je seveda neposredno povezano s stanovanjskim standardom, ki je praviloma višji v novejših soseskah. Med razlogi za nezadovoljstvo s stanovanjem se na prvem mestu povsod pojavlja neustrezna velikost stanovanja. Najpogosteje se zaradi premajhnih stanovanj pritožujejo družine z otroci. Drugi razlog nezadovoljstva je neustrezna kvaliteta stanovanja. Po pričakovanjih so ta razlog izpostavili predvsem prebivalci v starejših blokovskih soseskah, na primer Litostrojski bloki, Savsko naselje in Na jami. Starejši stanovanjski bloki in stanovanja bi bila potrebna temeljite prenove, ki pa je za mnoge stanovalce prevelik strošek. Z lokacijo je nezadovoljen le manjši del gospodinjstev. Med ostalimi razlogi za nezadovoljstvo s stanovanjem se v manjši meri pojavljajo še slabi odnosi s sosedi, hrup in premalo zasebnosti.

Iz opravljene ankete sledi, da se namerava po posameznih soseskah preseliti med $12 \%$ in $46 \%$ vseh anketiranih gospodinjstev, največ v soseskah Nove Fužine in Bratov Babnik, nekoliko manj v soseskah Litostrojski bloki, Na Jami, Brilejeva in Savsko naselje, najmanj pa v soseskah Trnovski pristan, Bežigrajski dvor in Nove Poljane (tabela 2). Višja potencialna selitvena mobilnost je značilna za najemnike in za mlajša gospodinjstva, nižja pa za ostarela. Ostarela gospodinjstva se za preselitev kljub nezadovoljstvu s stanovanjem ne odločajo tudi iz nekaterih drugih, sociopshiholoških razlogov (navajenost na določeno okolje, strah pred spremembo, negotovost, strah pred finančno izgubo pri menjavi nepremičnine). Po drugi strani je visok delež mlajše in srednje generacije, ki načrtuje preselitev. Med razlogi za preselitev je v vseh območjih anketiranja na prvem mestu želja po bivanju v enodružinski hiši. Velik del gospodinjstev namerava poiskati ustreznejše (večje) stanovanje v drugem delu mesta in le manjši del ima namen ostati v istem delu mesta, le v ustreznejšem stanovanju. Med najemniki in mlajšimi osebami, ki živijo s starši je najpogostejši razlog za preselitev želja po lastnem stanovanju. Tako ugotovljena potencialna prostorska mobilnost prebivastva opozarja na nekatere 
procese, ki bodo v prihodnosti preoblikovali socialnogeografsko zgradbo mesta. Iz ugotovitev našega anketiranja sledi, da bo suburbanizacija ostala najizrazitejši proces socialnogeografske preobrazbe mesta. Največje spremembe lahko pričakujemo v območjih s prevlado mlajše in srednje generacije, kot so na primer novejše blokovske soseske. Zanimivo je, da je delež gospodinjstev, ki se namerava preseliti, pogosto višji od deleža gospodinjstev, ki svojim stanovanjem ni zadovoljen. Gre za gospodinjstva, ki si želijo izboljšati stanovanjski standard, čeprav niso "nezadovoljna" s svojim stanovanjem. Odločitev za selitev torej ni pogojena le z nezadovoljstvom s sedanjimi bivalnimi razmerami gospodinjstva, temveč tudi z družinskim in socioekonomskim položajem.

Vrednotenje kvalitete bivalnega okolja je ena izmed osnovnih vsebin behavoiurističnega pristopa $\mathrm{v}$ urbani geografiji. Zaznavanje, vrednotenje in ocenjevanje bivalnega okolja s strani prebivalstva je seveda močno subjektivno in pogojeno z mnogimi dejavniki, od psiholoških in socialnih, do trenutnega razpoloženja anketiranca. Številne raziskave so opozorile, da posamezne skupine prebivalcev različno sprejemajo vplive in informacije o okolju (Špes, 1998, str. 13). Dejavniki, ki vplivajo na različno razumevanje, dojemanje okolja in ki modificirajo predstave o okolju pri različnih skupinah ljudi, so združeni v skupino socialnogeografskih filtrov (Špes, 1998, str. 13). Tako Špesova v svoji raziskavi o zaznavanju degradiranega okolja s strani prebivalstva izbranih urbanih območij v Sloveniji navaja šest socialnogeografskih filtrov, ki vplivajo na zaznavanje in vrednotenje okolja: starostna struktura, izobrazbena in poklicna sestava, ekonomska moč in premoženjsko stanje, stopnja navezanosti in odvisnosti od narave, kulturno, versko in nacionalno poreklo ter osebni motivi, čustva in politična usmeritev (Špes, 1998, str. 13-15). Gold tako povdarja, da je zadovoljstvo z ožjim bivalnim okoljem sicer pomemben kazalec njegove dejanske kakovosti, a je vendarle v precejšnji meri odraz subjektivnega vrednotenja. Od sprejemanja in zaznavanja okolja pa so odvisne reakcije in odločitve posameznika (pasivno sprejemanje, odselitev, izboljšanje okolja...), ki posredno vplivajo tudi na socialnogeografsko zgradbo mesta, na primer koncentracija prebivalstva $\mathrm{z}$ višjim socioekonomskim položajem $\mathrm{v}$ območjih $\mathrm{z}$ boljšimi bivalnimi razmerami in koncentracija nižjih socioekonomskih skupin prebivalstva $\mathrm{v}$ degradiranih območjih.

V naši raziskavi so prebivalci ocenili svoje bivalno okolje po šestih kriterijih: splošna urejenost in čistoča, ekološke razmere, medsosedski odnosi, oskrba in storitve, prometne razmere in varnost. Kvaliteto bivalnega okolja so ocenjevali s petimi vrednostnimi stopnjami: zelo dobro, dobro, povprečno, slabo in zelo slabo. Posamezne odgovore smo točkovali z vrednostmi od 5 za odgovor "zelo dobro" do 1 za odgovor "zelo slabo". V tabeli 3 so prikazane povprečne vrednosti vrednotenja bivalnega okolja, ki smo jih izračunali na osnovi točkovanja odgovorov. 
Tabela 3: Povpr. vrednosti vrednotenja bivalnega okolja po območjih anketiranja

\begin{tabular}{|c|c|c|c|c|c|c|c|}
\hline & 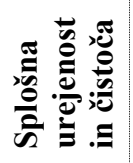 & 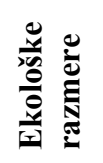 & 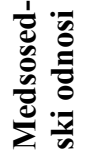 & 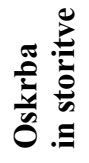 & 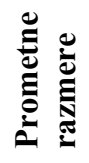 & $\begin{array}{l}\overline{\bar{v}} \\
\stackrel{\Xi}{\bar{E}} \\
\bar{\nu}\end{array}$ & $\frac{\vec{\pi}}{\frac{\pi}{E}}$ \\
\hline Litostrojski bloki & 2.88 & 2.97 & 3.57 & 3.82 & 3.62 & 3.49 & 3.39 \\
\hline Na Jami & 3.24 & 3.01 & 3.50 & 4.28 & 3.31 & 3.23 & 3.43 \\
\hline Savsko naselje & 3.26 & 2.82 & 3.47 & 3.94 & 3.12 & 3.37 & 3.33 \\
\hline Nove Fužine & 3.13 & 3.16 & 2.93 & 3.87 & 3.73 & 2.92 & 3.29 \\
\hline Bratov Babnik & 2.88 & 3.08 & 3.37 & 3.50 & 3.75 & 2.52 & 3.18 \\
\hline Trnovski pristan & 3.50 & 3.28 & 3.46 & 3.88 & 2.80 & 3.72 & 3.44 \\
\hline Brilejeva & 3.09 & 3.13 & 3.30 & 3.83 & 3.54 & 2.85 & 3.29 \\
\hline Bežigrajski dvor & 4.49 & 4.10 & 3.32 & 4.20 & 3.89 & 4.28 & 4.04 \\
\hline Nove Poljane & 4.14 & 3.58 & 3.76 & 3.22 & 3.20 & 3.36 & 3.54 \\
\hline Skupaj & 3.40 & 3.23 & 3.41 & 3.84 & 3.44 & 3.30 & 3.43 \\
\hline
\end{tabular}

Pri ocenjevanju splošne urejenosti in čistoče so med posameznimi soseskami precejšnje razlike. Zelo dobro so urejenost in čistočo ocenili prebivalci sosesk Bežigrajski dvor in Nove Poljane, dobro tudi v soseski Trnovski pristan. V ostalih soseskah prevladuje odgovor povprečno in slabo. Najslabše so urejenost in čistočo ocenili v soseskah Litostrojski bloki in Bratov Babnik. Anketiranci so izpostavil predvsem problem neurejenih in premajhnih otroških igrišč ter neurejene in slabo vzdrževane zelene površine. Tudi pri ocenjevanju ekoloških razmer je največ prebivalcev zadovoljnih v soseskah Bežigrajski dvor in Nove Poljane. V vseh soseskah je značilna velika razpšenost odgovorov, kar pomeni, da imajo prebivalci zelo različno mnenje o ekoloških razmerah v svoji soseski. Medsosedske odnose je velik del anetirancev ocenil kot dobre, precej tudi kot povprečne. Slabše so medsosedske odnose ocenili v soseski Nove Fužine. Kvaliteta oskrbe in storitev je bila med vsemi elementi vrednotenja bivalnega okolja ocenjena najbolje. Tako $\mathrm{v}$ vseh soseskah prevladujejo odgovori "zelo dobro" in "dobro". Najbolj so z oskrbo in storitvami zadovoljni v soseskh blizu mestnega središča (Na Jami, Bežigrajski dvor) ter v večjih soseskah (Nove Fužine, Savsko naselje). Nekoliko manj so z oskrbo in storitvami zadovoljni le v sosekah Nove Poljane in Bratov Babnik. Pri ocenjevanju prometnih razmer so anketiranci zelo neenotni. To je posledica različnega obnašanja posameznih skupin prebivalstva $\mathrm{v}$ prometu. Lastniki osebnih vozil so izpostavljali pomanjkanje parkirnih prostorov, predvsem v starejših soseskah (Na Jami, Litostrojski bloki, Savsko naselje), zato so prometne razmere ocenjevali kot slabe. Uporabniki javnega prevoza so ocenjevali predvsem dostopnost 
in učinkovitost mestnega potniškega prometa. Relativno dobro so prometne razmere ocenili v soseskah z dobro prometno dostopnostjo, na primer v bližini obvoznice. Varnost so anketiranci ocenli najbolje v soseski Bežigrajski dvor, kjer imajo urejeno varovanje s strani varnostne službe v celotni soseski. Kot dobro in povprečno so varnost ocenili v večini preostalih sosesk. Najslabše so varnost ocenili v soseskah Bratov Babnik in Nove Fužine, kjer so izpostavili problem vlomov v stanovanja, krajo avtomobilov, vandalizem in mladostiško prestopništvo.

Analizo vrednotenja kvalitete bivalnega okolja lahko zaključimo z ugotovitvijo, da je zaznavanje in vrednotenje kvalitete bivalnega okolja močno subjektivno in pogojeno s številnimi dejavniki, ki jih lahko ponazorimo z socialnogeografskimi filtri. Ocenjevanje posameznih elementov bivalnega okolja je pokazalo, da med posameznimi območji anketiranja ni zelo velikega odstopanja, čeprav se dejanska kvaliteta bivalnega okolja precej razlikuje. To potrjuje hipotezo, da so prebivalci $\mathrm{z}$ nižjim socioekonomskim statusom bolj prizanesljivi pri ocenjevanju svojega bivalnega okolja. Nadalje se je tako izkazalo, da imajo prebivalci posameznih sosesk do določenih elementov bivalnega okolja bolj »usklajeno« mnenje, ob drugih se njihovi odgovori zelo razlikujejo. Tako posamezni element bivalnega okolja nekateri anketiranci $\mathrm{v}$ istem območju anketiranja vrednotijo zelo slabo, drugi pa zelo dobro. To le potrjuje veliko subjektivnost zaznavanja in vrednotenja bivalnega okolja $\mathrm{s}$ strani prebivalstva in razlike pogojene s »socialnogeografskimi« filtri.

\section{BEHAVIOURISTIČNO PROUČEVANJE STANOVANJSKIH OBMOČIJ KOT ELEMENT URBANISTIČNEGA PLANIRANJA}

Ugotavljanje odnosa prebivalstva do svojega bivalnega okolja je pomebna osnova za uspešno in učinkovito urbanistično načrtovanje. Za uspešno načrtovanje razvoja mest, predvsem načrtovanje usmerjanje stanovanjske gradnje je tako med drugim potrebno :

- Poznavanje socialne sestave prebivalstva in procesov socialne preobrazbe $\mathrm{v}$ posameznih delih mesta.

- Proučevanje vrednotenje kvalitete bivalnega okolja posameznikov in posameznih socialnih skupin prebivalstva.

- Ugotavljanje bivalnih potreb in preferenc posameznikov in posameznih socialnih skupin prebivalstva.

- Ocenjevanje ustreznosti stanovanjskega fonda.

- Predvidevanje bodočih selitvenih tokov kot elementa socialnogeografske preobrazbe mesta. 


\section{Literatura:}

Brezar, Vladimir, 1995. Stanovanjska izgradnja v Sloveniji včeraj in danes, Urbani izziv, 28 - 29,

Carter, Harold, 1995. The Study of Urban Geography. Arnold,

Hall, Tim. 1998. Urban Geography. Routtledge,

Jackson, Peter, Smith, Susan J., 1984, Exploring Social Geography, London,

Knox, Paul, 1995. Urban Social Geography, Longman Scientific and Technical

Liebmann, Heike, Rietdorf, Werner, 2001. Grosssidlungen in Ostmitteleuropa zwischen Gestern und Morgen. Europa Regional, letnik 9, številka 2,

Rebernik, Dejan. 2000. Socialnogeografska zgradba Ljubljane, Ljubljana Geografija mesta, str. 59-68.

Stanovnik, Tine, 1995. Nekaj ekonomskih problemov stanovanjskega področja v Sloveniji. Urbani izziv, 28 - 29,

Stollberg-Barkley, Dorte, 2001. Grosssidlungen in Grossbritannien. Europa Regional, letnik 9, številka 1,

Špes, Metka, 1998. Degradacija okolja kot element diferenciacije urbane pokrajine. Geographica Slovenica, 30,

\section{URBAN GEOGRAPHY OF HIGH-RISE HOUSING ESTATES AND ITS APPLICATION IN URBAN PLANNING}

\section{Summary}

Research about perception and evaluation of living environment by the population of high-rise housing estates in Ljubljana and its potential application in urban planing is presented in the paper. By the use of questionnaire surveys in different high-rise housing estates characteristics of residential location decisions and potential intraurban migrations are defined.

In Slovenia, as elsewhere in Europe, intensive high-rise housing development took place after Second World War. The main reason for this was an acute housing shortage, mainly in urban areas. Housing shortage was a consequence of several factors, similar to those in Western and Central Europe: war destruction of housing, fast urbanisation, industrialisation and connected strong rural-urban migrations.

In European urban geography the study of high-rise housing estates became an important area of research, as it is considered the most problematic part of housing. High-rise housing estates are subject to processes of physical and social degradation, concentration of "marginal" social groups, rise of crime 
rates, and other socially deviant forms of behaviour. Direct consequences of such processes are negative image of high-rise housing estates in public, falling real estate prices and out migration of population.

In Ljubljana the importance of public housing was above Slovene average. The share of public housing construction reached between $60 \%$ and $80 \%$. In mid seventies up to 3000 flats in high-rise housing estates was built per year. In the second half of the eighties public housing construction declined as in the rest of the country. In the nineties only about 500 flats in high-rise housing estates were built per year. High-rise housing estates thus represent the most wide spread form of residential areas in Ljubljana. Out of 110000 housing units in Ljubljana, 60000 are in high-rise housing estates built after the Second World War.

Quality of life in urban areas should be judged upon wide rage of physical, environmental, social, economic and health indicators With behavioural urban geography studies of evaluation of the quality of life by local population were undertaken. In our research we tried to delineate the basic characteristics of evaluation of quality of life in high-rise housing estates in Ljubljana and its impact on decision- making concerning location and type of housing. In this regard we also tried to measure and predict potential residential mobility in different housing estates in the city. Six hundred questionnaires were carried out in 9 different high-rise housing estates in Ljubljana.

Up to 1990 residential mobility in Slovene urban areas was very low. This was conditioned by low degree of private ownership and underdeveloped housing market, but also by social and psychological factors. The results of our research show an increased residential mobility after 1991. This can be attributed mainly to the development of housing market due to privatisation of public housing sector. Residential mobility is particularly high in high-rise housing estates, in the first place among tenants. In older housing estates the share of first owners of flats is only about 25 to $30 \%$. More than $25 \%$ of inhabitants moved in in the last 10 years.

Most individuals or household move by choice. The main reason to move is thus the level of satisfaction with living conditions of an individual household. According to our research between $10 \%$ and $40 \%$ of households in different high-rise housing estates in Ljubljana is not satisfied with their actual living conditions. In general lines, higher percentage of households not satisfied with living conditions is characteristic for older and larger high-rise housing estates.

Potential residential mobility in the next five years was estimated. It varies between $12 \%$ in housing estate Nove Poljane and $46 \%$ in housing estates Bratov Babnik and Nove Fužine. Different types of households exhibit different residential mobility. High potential residential mobility is so characteristic 
for younger households, particularly families with young children and young couples. Very low potential residential mobility is on the other hand typical for older households, which do not intent to move in spite of unsatisfactory living conditions. The main reason to move is a preference to live in a singlefamily house.

Evaluation of quality of life was divided into six categories: general quality of living environment, ecological characteristics of environment, neighbourhood relations, quality of services, traffic conditions and security. Responses were given 1 to 5 points, according to level of satisfaction. Mean values of evaluation of quality of life show that there are quite important differences among housing estates included in our research.

General quality of life was evaluated as good and very good in new highrise housing estates. In older housing estates it was evaluated as average or bad, mainly because of poor quality and maintenance of green areas, children playgrounds and other collective facilities. Different social groups evaluated ecological characteristics of environment in a very different way. It is typical that people with higher socio-economical status are more critical. Neighbourhood relations were in general evaluated as good to average, better in smaller housing estates. Quality of services was in all housing estates evaluated as good or even very good. Traffic conditions were evaluated in a very different manner by different groups of population, depending of the use of public or private transport. Security was evaluated as average.

For effective and successful urban planning knowledge of perception and evaluation of living environment by local population is very important. In this regard, several urban geographical research topics are of crucial importance:

- research of social structure and transformation of urban areas

- research of perception and evaluation of living environment by individiuals, households and social groups

- research of housing needs and preferences of different social groups of population

- research of existing and future intraurban migration and its impact on social transformation of residential areas 